\title{
A NEW BALL SET FOR TUBE SPINNING OF THIN-WALLED TUBULAR PARTS WITH LONGITUDINAL INNER RIBS
}

\section{Khaled I.E. Ahmed}

Mechanical Engineering Department, Assiut University, Assiut, 71516, Egypt,e-mail:dr.kh.ahmed@gmail.com

\section{(Received October 12, 2010 Accepted December 15, 2010)}

Tube spinning is one of the old incremental forming manufacturing processes. Recently, tube spinning using balls as forming tools, has been extensively utilized in producing tubular components with longitudinal or helical internal gear teeth, internal grooves or internal ribs. Thin-walled tubular parts with longitudinal inner ribs emerge in order to adapt to the development of aeronautic, aerospace and military industry. Recent development of tube spinning of macro and micro inner grooved tubes and inner geared drums face many challenges. The most important ones are; material built up formation in front of the forming balls, material folding at the tube inner surface, and the forming mandrel failure due to load fluctuations at the root of the forming tooth. These problems have been addressed separately in the literature without a unified approach to simultaneously overcome them. The current study proposes a new ball set design that is claimed to be able to overcome these problems simultaneously. A finite element simulation model for the conventional and the new proposed designs is built and verified. The conventional ball set contains four balls lie in the same plane. The proposed design contains 24 balls distributed in four planes, having 6 balls in each plane. The first plane is set to suppress the built up formation, the second and third plane are set for the main forming process, the fourth plane is set for suppressing the load fluctuation. Each two consecutive planes are shifted by $60 \mathrm{deg}$ from each other to suppress the folding creation. By examining the achieved results, the new design has shown the potential to significantly reduce the built up formation in the front of the forming balls. Also, the reactions at the inner surface of the spun tube have shown significant improvements in both the radial load fluctuation which is responsible of the folding problems and the load in the tangential direction which is responsible of the tooth root failure.

KEYWORDS: Tube spinning, Ball spinning, Spinning Rollers, Finite element, Build up formation, Folding, Inner ribs, Grooved tubes, Micro grooved fins, Internal gear forming, Metal forming

\section{INTRODUCTION}

Tube spinning is known in industry by variety of names such as; shear forming, tube spinning, flow turning, flow forming, rotary extrusion, roll extrusion, hydrospinning, and rotoforming [1-2]. All these terms describe the basic process of producing tubular products over a rotating mandrel by the action of an external roller. The differences 
generally pertain to the type of rollers, mandrels, and mechanisms used in producing these tubes [1-2]. The basic mechanics and components of tube spinning are shown in Figures (1\&2). The pre-form is placed on a rotating mandrel, while the forming roller is traversed axially reducing the pre-form thickness and elongating its length parallel to the mandrel axis [1]. The forming rollers may traverse either in the same direction of tube elongation (forward tube spinning), or in the opposite direction of the tube elongation (backward tube spinning) [1-2]. Most of tube spinning applications use rollers located outside the tube having the mandrel defining its inner diameter, (external spinning) [1-2]. However, in some applications the rollers may be located inside the tube having the mandrel defining its outer diameter (internal spinning) [1].
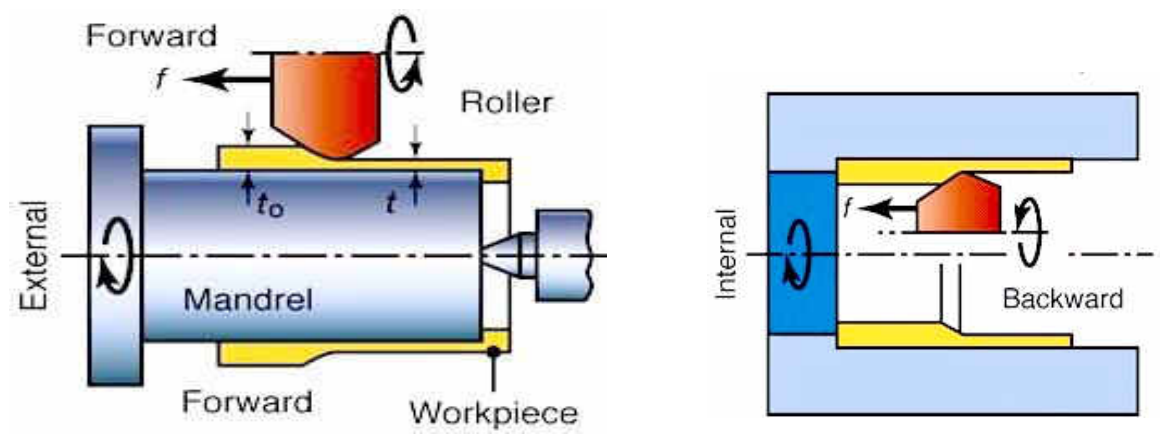

Figure 1: Basic mechanics of the two processes of tube spinning using rollers [1].

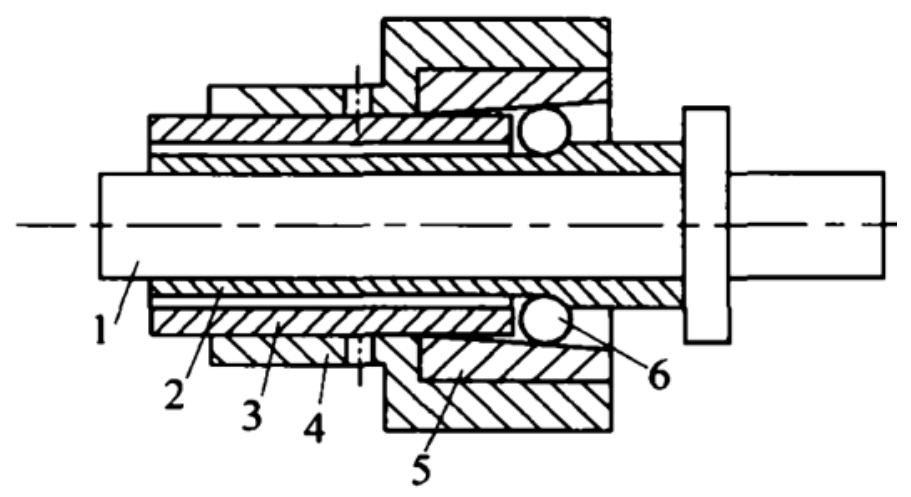

1-Mandrel;

2-Spun part;

3-Screw tube;

4-Supporting ring;

5-Conical ring;

6- Forming Ball

Figure 2: Schematic diagram of ball spinning [12]

Typical products of tube spinning include pressure vessels, automotive parts, space shuttles components, rockets and missiles parts and a great variety of very high strength with light weight tubular components [1]; also refer to Figures (3\&4). Since 1950 to 1970 , the forming tools in tube spinning were mainly rollers [3]. The use of balls as forming rollers was introduced in 1970 to get more precise tubular components [3]. Only few investigations were then done to study the process of tube spinning using balls [3-5]. Recently, tube spinning using balls has been extensively utilized in producing tubular components with longitudinal or helical internal gear teeth, internal grooves or internal ribs [6-15]. Thin-walled tubular parts with longitudinal inner ribs emerge in order to adapt to the development of aeronautic industry, aerospace industry 
and military industry [10]. Traditional plastic working processes have been unable to meet the demands of producing such parts. As a successive and local plastic deformation process, backward ball spinning plays a significant role in forming thinwalled tubular parts with longitudinal inner ribs [10]. Also, internal geared tubular parts produced by tube spinning are more favorable than that produced by cutting because the latter cuts the gear fibers at teeth corners while the former form it with the teeth profile [11]. Tube spinning has shown good capability of producing microgroove fin-inside tubes that used to enhance the heat transfer and capillary geometry in micro-heat pipes [14]. Superiority of tube spinning over tube sinking in producing micro fin tubes is clearly shown in Figure 4.



a- Helical internal gear [11]

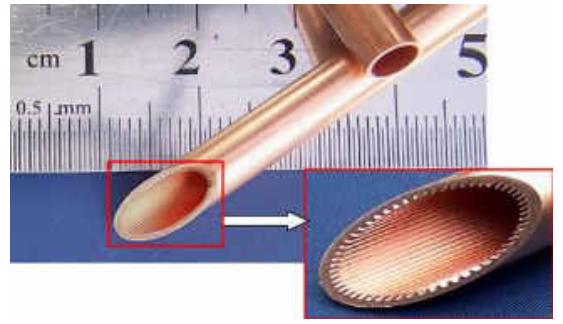

b- Micro-groove fin-inside tubes of copper [14]

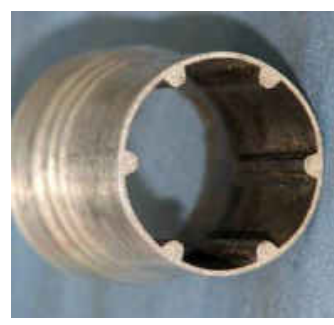

c- Longitudinal ribs [15]

Figure 3: Typical tubular components produced by tube spinning:

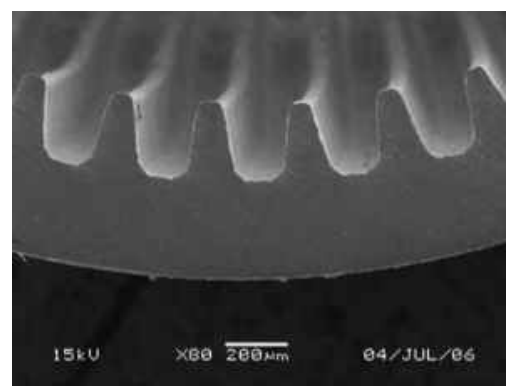

a- Using tube spinning [14]
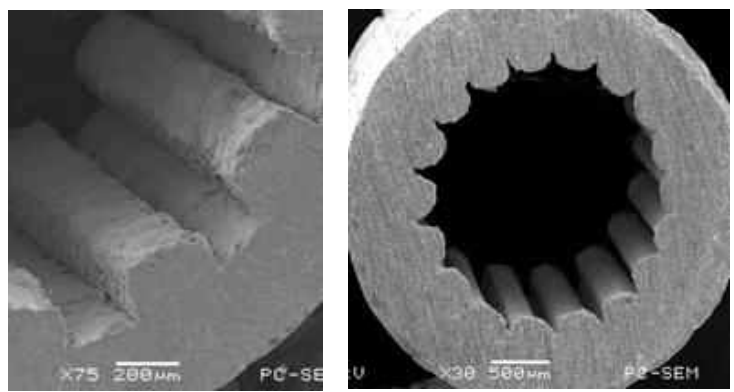

b- Using tube sinking [17]

Figure 4: Comparison between micro-groove fin-inside tubes produced by tube spinning and tube sinking.

Generally, the final product of tube spinning process using balls is mainly affected by; forming ball diameter, thickness reduction per pass, and formed tube ductility [3-5]. Same characteristics have been observed for inner grooved tubes [1116]. The formation of the inner ribs begins at certain critical ball size, after which, the height of the formed ribs increases with the increase of the ball size $[10,12,14$, and 15]. This relation is controlled by the tube dimensional accuracy and surface quality which are significantly degraded with the increase of the ball size [14-15]. The inner ribs can not be formed without reducing the tube wall thickness. The height of the formed ribs increases with the increase of the tube thickness reduction per pass [10, 12 and 14]. Same behavior is observed for formed tube material ductility [14]. Contrarily, the thicker the formed tubes the smaller the height of the formed ribs [10]. Figure 5 shows the effect of the ball size, tube material ductility, tube thickness reduction and tube thickness on the formation of the inner ribs [10, 14 and 15]. 

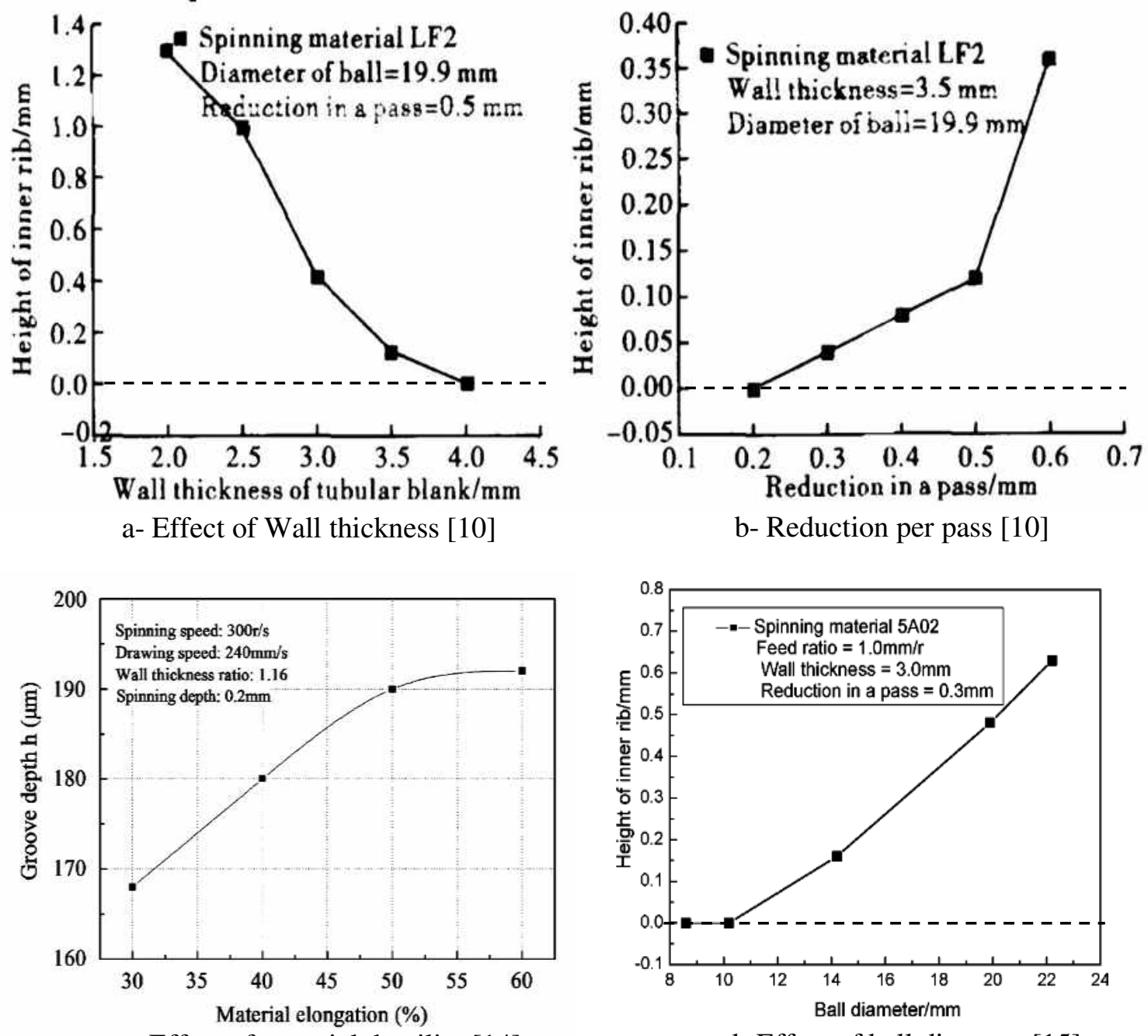

c- Effect of material ductility [14]

d- Effect of ball diameter [15]

Figure 5: The effect of process parameters on the formed rib height;

In the process of forming inner ribs by tube spinning, the ball diameter is fairly large that leads to significant gabs between successive balls which give an opportunity to the partially formed rib to elastically leave the mandrel groove, creating a folding when the next ball squeezes it back to that groove [6 and 13]. This folding creation is a significant source of longitudinal cracks (Figure 6) [14]. Also this gab causes fluctuation in the forming loads on the mandrel teeth and leads to short life of the toothed mandrel (Figure 7) [11]. Each of these two defects has been addressed separately in the literature with no solution to simultaneously overcome them both. A solution for folding was proposed focusing on grooving the tube gradually by combining tube spinning with tube expanding techniques [6]. As for the groove root failure, the proposed solution focused on reducing the number of forming balls to one ball with an intermediate ring between the forming ball and the formed tube surface [11]. 

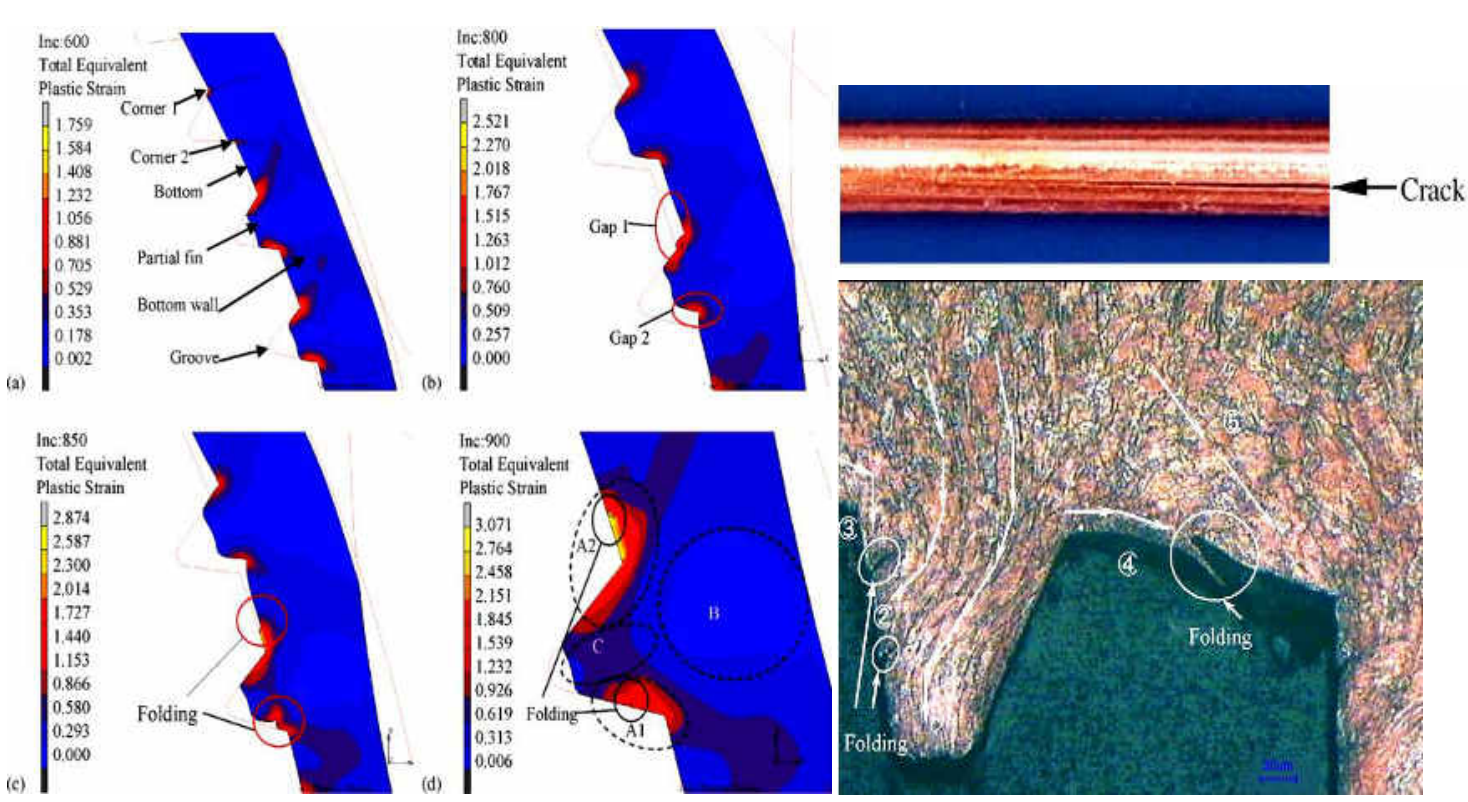

Figure 6: Scenario of folding creation during tube spinning of inner grooved tubes with a metallographic picture of the cross-section of the inner grooved tube and an external picture of the cracked tube [13-14]
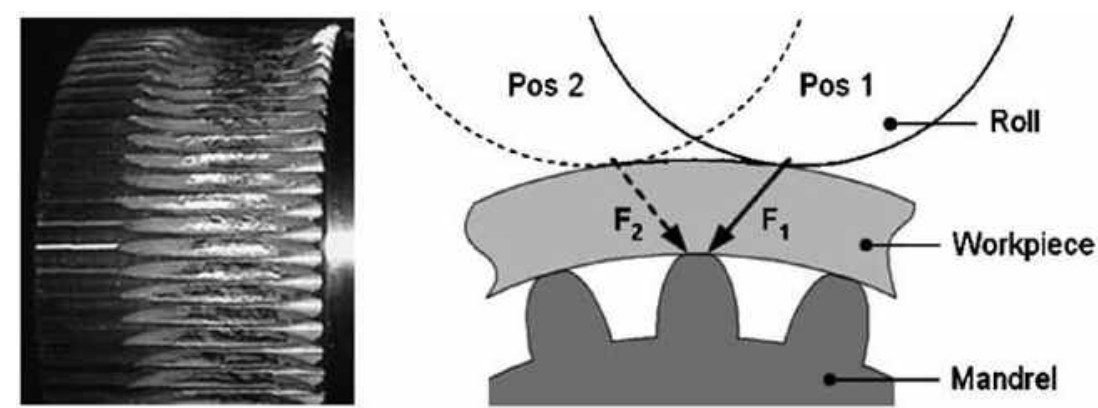

Figure 7: The left picture shows root breakage at the mandrel's teeth. The cause of this specific failure is illustrated on the right picture [11].

As mentioned previously tube spinning is an incremental nonsymmetrical metal forming process. These characteristics require three dimensional modeling with complicated contact capabilities and very small load steps. This combination requires huge CPU time and computing resources. These difficulties lead to many approximations in finite element simulation models. Kemin et al. (1997) [18] have reported the difficulties of building an in house code to study the tube spinning process. Most of these difficulties arise due to the tide adjacent of plastic and elastic zones under the deforming roller. In another attempt, Kemin et al. (1997) [19] and Xue et al. (2001) [20] have studied one third of the deformed tube, assuming the deformation has reached a middle stage as an initial condition before starting the solution (Figure 8). These simulations were focusing on distinguishing between plastic and elastic zones under the forming rollers. 
Hua et al. (2004) [21] have shown a full simulation, by ANSYS, using three rollers setup to study the residual stresses in the spun tubes due to process parameters. As an extension of that work, Hua et al. (2005) [22] have presented more results from their model showing forming loads, built up formation, bell mouth, and bulging modes. In these studies, the simulation results were compared to some experimental findings qualitatively with no quantitative evaluation for the simulation results. Moreira et al. (2008) [22], have presented similar model, using ABAQUS, studying the effect of the pre-treatment of the pre-form tube on the final spun tube. They have concluded that the simulation results strongly depend on the way the pre heat treatment is numerically prescribed.

Parsa et al. (2008) [24], have presented more extensive model for tube spinning using two rollers to measure the formability of the process according to the process parameters. They have used explicit dynamics scheme to get faster and more accurate results. Their simulation results were compared with experimental findings from literature. They have concluded that simulation of flow forming flow formability are inherently very time-consuming and involves large computational resources. Further conclusion was stating that the simulation results are not in match with the experimental findings, however the trends of the simulation and experiments are the same which is a good measure prior any experimental work.

Wong et al. (2008) [25], have presented a finite element model for multi pass flow forming from a thick flat disk as a pre-form instead of the standard thick tube. In this model they have used just one roller as forming tool for all passes. They have investigated the process parameters such as roller feed and reduction per pass on the end product. Similar to most of the previous works, comparisons with experimental work were just limited to qualitative evaluation. They have concluded that although FEM is an effective tool to optimize process parameters, computational time and resources remain as the main barrier for its privilege usage due to the incremental nature of the flow forming process.

Roy et al. (2009) [26], have pointed out the lacke of quantitative comparisons between the previous finite element simulations and experimental investigations. They have presented extensive experimental investigations for the plastic strain evolution during the flow forming process to help in validating any further finite element simulation of the flow forming process.

Finite element simulation of tube spinning using balls was firstly presented by Doege et al. (1996) [27]. A comparison between explicit dynamic scheme using ABAQUS and implicit scheme using MARC has been presented. Their model is assumed pre-deformed to a middle stage as an initial condition before starting the solution. The explicit dynamic model has consumed the same computing time as that for implicit model with half number of elements. They have presented a qualitative comparison between the measured micro-hardness and the predicted plastic strains.

Jiang et al. (2007) [12] have presented a finite element simulation for tube spinning of tubular parts with longitudinal inner ribs using DEFORM 3D (Figure 8). The model has utilized the re-meshing capabilities of the code to overcome the mesh distortion at groove entrance and under the forming balls. The sources of convergence difficulties have been addressed and discussed to achieve a successful simulation. The study has been then extended (Jiang et al. (2009) [15] and Jiang et al. (2009) [16]) to predict the rib height and quantitatively compare it with experimental findings. 
Significant discrepancies have been observed between the experimental and simulation results (Figure 8).

Zhang et al. (2007) [13] have presented a 2D simulation model for the tube spinning tubular parts with longitudinal inner ribs to study the folding sources. The model considered half of the circular tube to reduce the computational time. The study has shown a qualitative comparison for the folding locations between the experimental and finite element simulation (Figure 6).

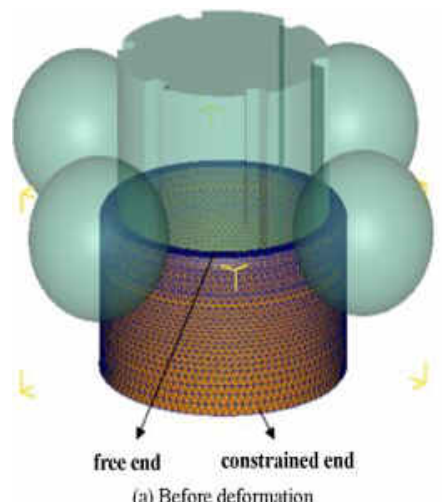

(a) Before deformation


Figure 8: Finite element model of ball spinning of the spun part and the comparison between finite element model and experimental measurements of the inner rib height. [15]

The aim of this work is to propose a new design of a forming ball set that able to reduce simultaneously the built up formation, folding and forming tooth breakage. Although, simulations of inner grooved tube by spinning using balls with updated Lagrangian finite element didn't show accurate quantitative results, the qualitative comparison would be enough to show the superiority of the proposed ball set design over the current one. The current study has three phases; in the first phase a simulation of the tube spinning of tubular parts using 4 balls is modeled. This phase focuses on the mechanics of tube thickness reduction exploring the forming loads, stresses and strains. In the second phase the same simulation model is adopted to be used in simulation the producing of a tubular part with four inner splines using the regular ball set. This phase focuses on the folding of the produced splines and the load fluctuation at the root of the forming mandrel. Then in the third phase a preliminary solutions are proposed and simulated for the new ball set showing its superiority over the regular one in reducing the built up formation, severity of folding formation and load fluctuations.

\section{FINITE ELEMENT SIMULATION}

Finite element simulation of metal forming processes, if well defined, works efficiently as a virtual testing setup. More flexibility, better mechanics understanding, and more efficient process development are the most powerful characteristics of virtual testing setups made of finite element simulations. Many powerful simulation packages are available in the market for research works. In the current work we have utilized simulation package ANSYS for creating our virtual testing setup for the tube spinning of regular tubes and inner grooved tubes. 
In the current work, the mandrel diameter is $12 \mathrm{~mm}$, the tube outer diameter before deformation is $20 \mathrm{~mm}$, and the reduction is $1 \mathrm{~mm}$ in the tube thickness. The tube material is pure Aluminum with initial yield of $40 \mathrm{MPa}$, work hardening exponents of 0.27 , and strength coefficient of $220 \mathrm{MPa}$.

The forming balls are assumed to be fully rigid. The regular tube mandrel is modeled by constraining the inner tube nodes in the radial direction. By using this modeling technique, the separation between the inner tube surface and the mandrel stem, during the deformation, may be easily evaluated based on the negative reactions of the radial forces of the constrained inner tube nodes. The balls are given rotation and axial displacement around the tube. The tube end is constrained in the axial and rotational directions. The axial movement of the balls is controlled with a feed value of $1 \mathrm{~mm} / \mathrm{rev}$.

\section{SPINNING OF A REGULAR TUBE USING 4 BALLS}

Figure 9, shows the finite element simulation model of the tube spinning of a tube over a circular mandrel using 4 balls. The forming ball diameter is $30 \mathrm{~mm}$ which is the minimum diameter that ensures pressure angle less than $21^{\circ}$ with thickness reduction of $1 \mathrm{~mm}$ [15]. The model used 8616 elements, 5896 nodes, 16544 DOF with a maximum wave-front of 55 . An axial displacement of $11 \mathrm{~mm}$ is solved by 756 load steps using 13838 accumulated iterations. The simulation was carried on an Intel Core 2 Due $2.2 \mathrm{GHz}$ PC with 3GB RAM. The total calculation time for this model was 30 hrs.


Figure 9: Finite element model of ball spinning of a tube over circular mandrel.

The deformed shape after $11 \mathrm{~mm}$ axial displacement of the balls is shown in Figure 10. The built up formation accumulates in the front of the balls, increasing the radial and tangential forces. Figure 11 shows the radial stresses at the outer surface of the deformed tube and its gradient through thickness. It is worth noting that the stresses are localized under the deforming ball and are vanished elsewhere. Stresses under the forming balls are one order of magnitude of the original yield stress while the forming loads are very small. This is the main advantage of tube spinning using balls.

By examining the radial stresses through the tube cross section, Figure 12, it is clear that the radial stresses have their largest value at the outmost tube surface under 
the forming ball, then decrease significantly to almost quarter of its value at the inner most surface. The figure also shows tensile radial stresses, red zones, in the inner

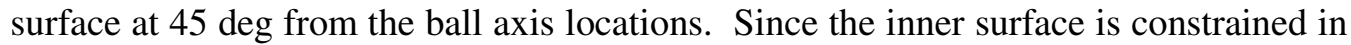
the radial direction, then this tensile radial stress is a measure for the amount of separation between the tube inner surface and the mandrel surface.

During the rotation of the balls for one cycle around the tube circumferential, each node in the tube inner surface gets compressed to and separated from the mandrel surface four times alternately (Figure 13). The compression is evaluated by the positive radial reaction for the tube inner node and the separation is evaluated by the negative radial reaction at the tube inner node. The node is at maximum compression when it is under the ball axis and maximum separation when it is at 45 deg from the forming ball axis. The amount of compression is increased as moving forward along the tube axis due to the increase of the built up formation.



a. Front View.

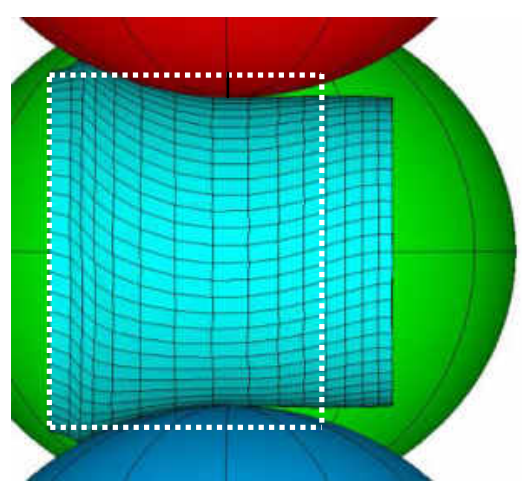

b. Side View

Figure 10: The partially deformed tube under the forming balls showing the edges of the pre-deformed tube;



Figure 11: Radial Stresses in MPa at the outside surface of the deformed tube. 


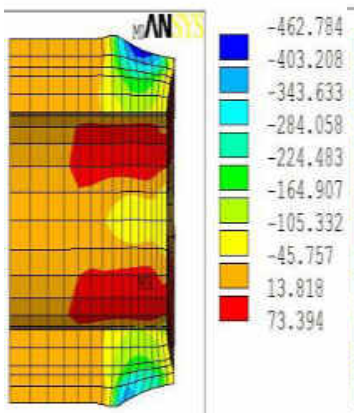

a. After three turns $(3 \mathrm{~mm})$

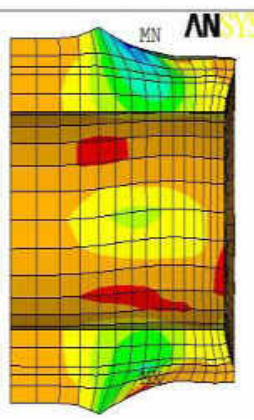

b. After six turns $(6 \mathrm{~mm})$

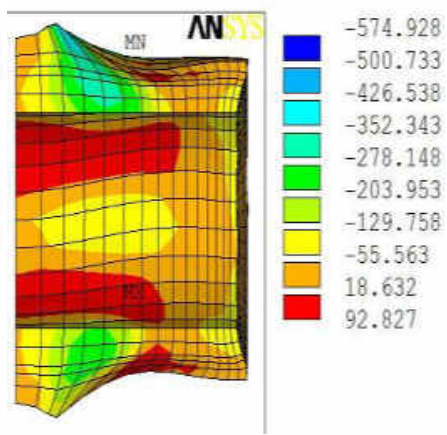

c. After nine turns $(9 \mathrm{~mm})$

Figure 12: Radial Stresses in MPa at the inner surface and cross section of the deformed tube.

The forming loads at the forming balls are mainly the axial loads and the radial loads. As shown in Figure 14, the radial loads are much higher (3 times) than that in the axial direction. This characteristic is another advantage of tube spinning, that the forming loads needed by the spinning machine are much lower than that required for the plastic deformation (Radial).

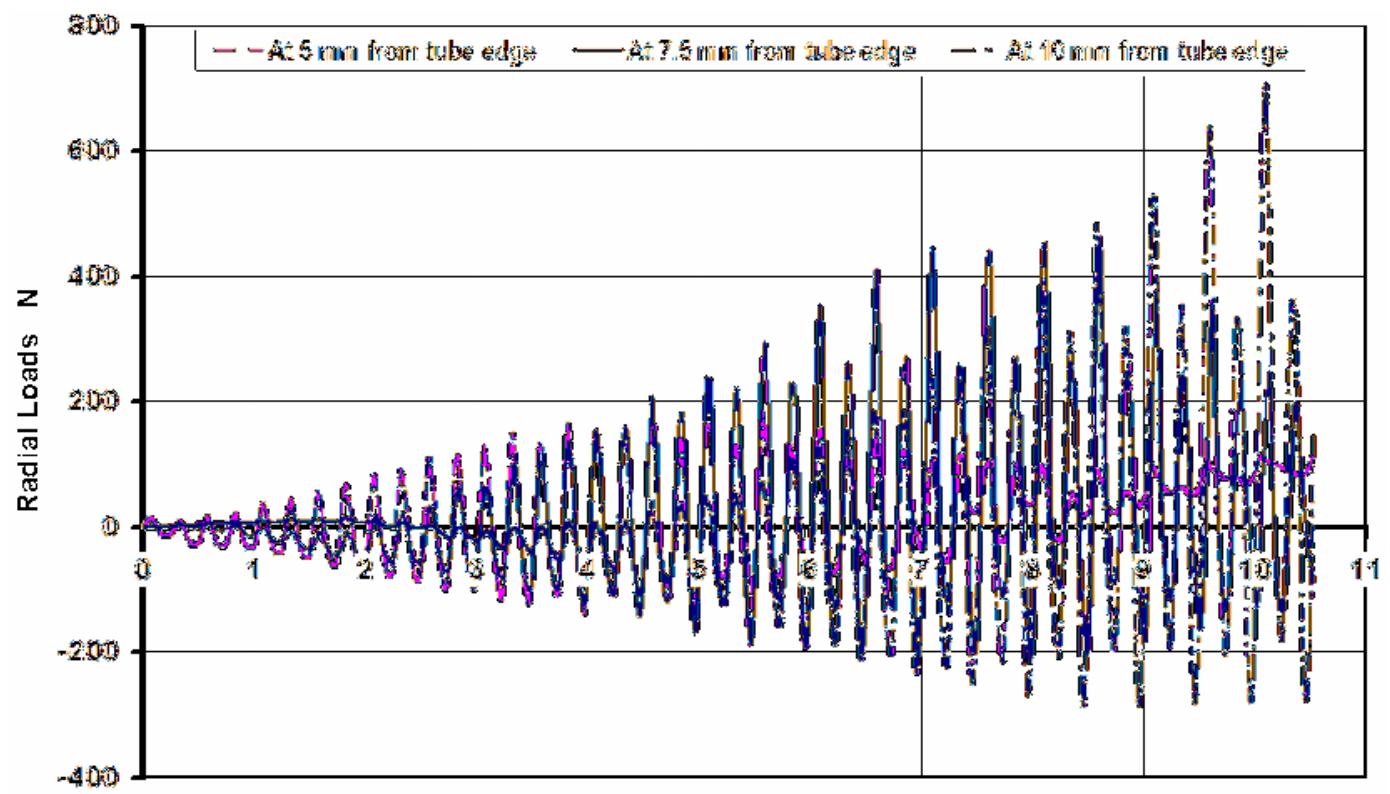

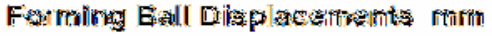

Figure 13: Radial Reactions at three locations along the tube inner surface 


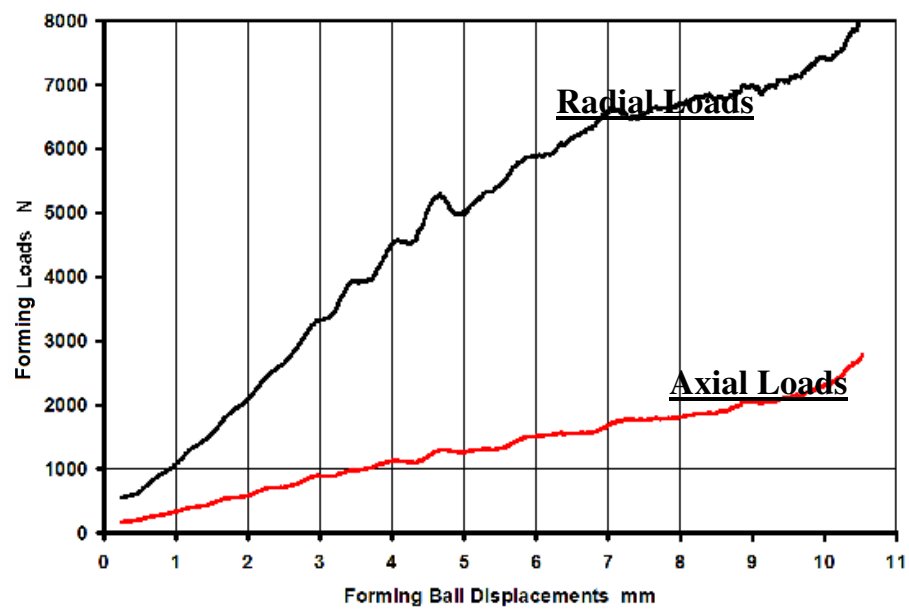

Figure 14: The radial and axial forming loads at one forming ball.

\section{SPINNING OF INNER GROOVED TUBE USING 4 BALLS}

In the second phase the same model, with little mesh enhancement for the inner tube surface is used to model the formation of an inner splined tube. The concept of modeling the forming mandrel by applying special boundary conditions pattern is applied again here. The mandrel inner surface is divided into 8 surfaces having each next surface constrained in the radial direction (Figure 15). The edges between these surfaces which represent the splines edges are constrained in the circumferential direction. The boundary conditions at the tube end and at the balls centers are the same as the previous model. Due to the deformation expected in the inner surface, its mesh density is increased to 11524 nodes for 14408 elements instead of 5896 out of 8616 elements. This finite element model creates 31756 equations with a maximum wave-front of 54. An axial displacement of $10 \mathrm{~mm}$ is solved by 686 load steps using 12435 accumulated iterations. The simulation was carried on the same machine with total calculation time of $53.4 \mathrm{hrs}$. The deformed shape after $10.5 \mathrm{~mm}$ of the forming balls axial displacement is shown in Figure 15.
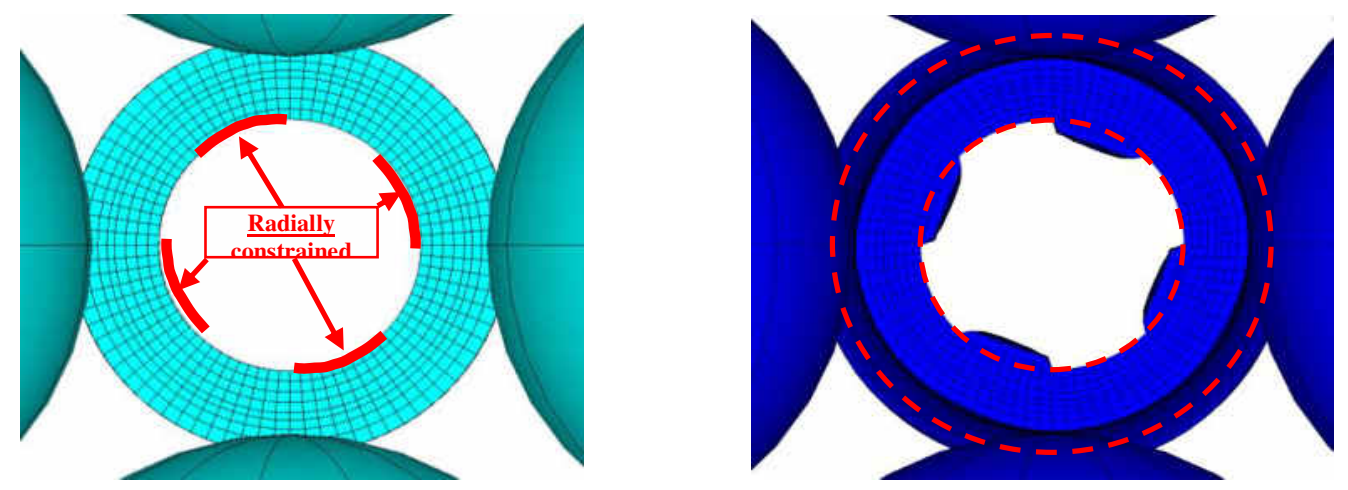

Figure 15: The finite element model of the tube spinning using balls for inner splined tube showing the deformed shape after $10 \mathrm{~mm}$ of forming balls axial displacements. 
Figure 16 shows the radial strain distribution at the outer and inner surfaces of the spun inner splined tube. The accumulation of the built up formation under the forming ball is responsible for the non-uniform spline thickness along the tube axis. The built up formation increases the total thickness reduction that increases the radial forming loads, which consequently increases the spline thickness.

Figure 17 presents the fluctuation in the tangential reactions at the spline edge. This fluctuation is a source of cracks at the root of the spline die formed in the mandrel. Also the fluctuation in the redial reactions represents the amount of separation between the tube inner surface and the mandrel surface. This separation is the main source of the folding defects during the tube spinning process. It is worth noting that the formation of splined tooth gives an opportunity to the accumulated built up formation under the forming balls to breathe out towards the splines. This explains the reduction in the forming loads, Figure 18, in the case of spline formation when compared to that in the previous conventional tube spinning. However, this breathing is responsible of the non-uniformity of the spline thickness along the tube axis.

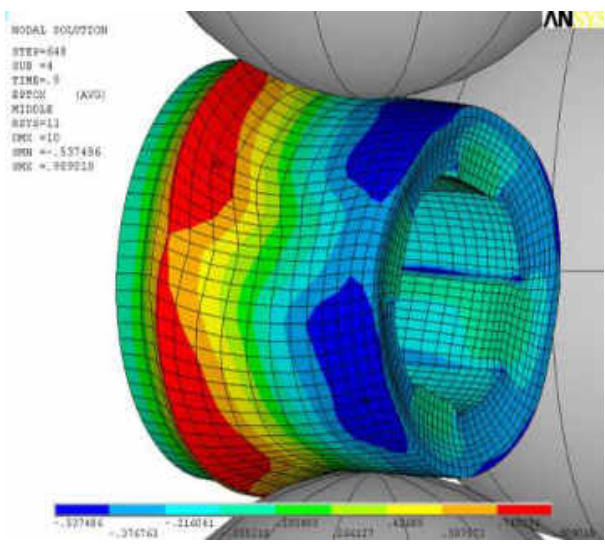

a. Outer surface radial strains showing the built up formation under the forming ball.

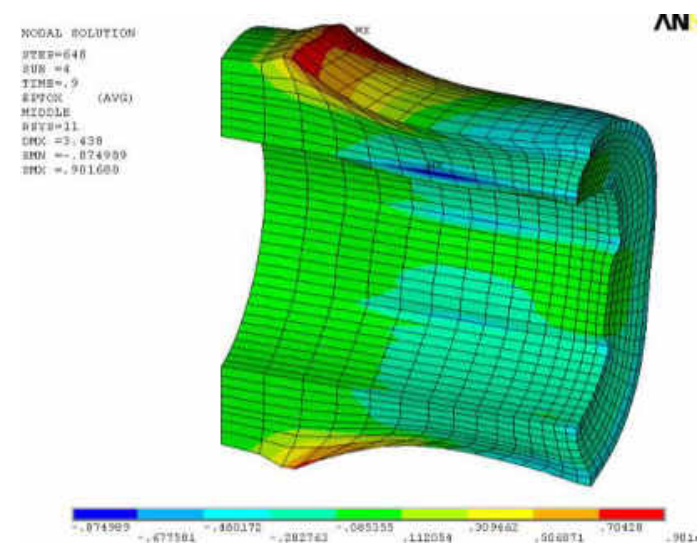

b. Inner surface radial strains showing the splined bulge due to thickness reduction increase

Figure 16: The radial strain in the spun inner splined tube after $10 \mathrm{~mm}$ balls axial displacement.

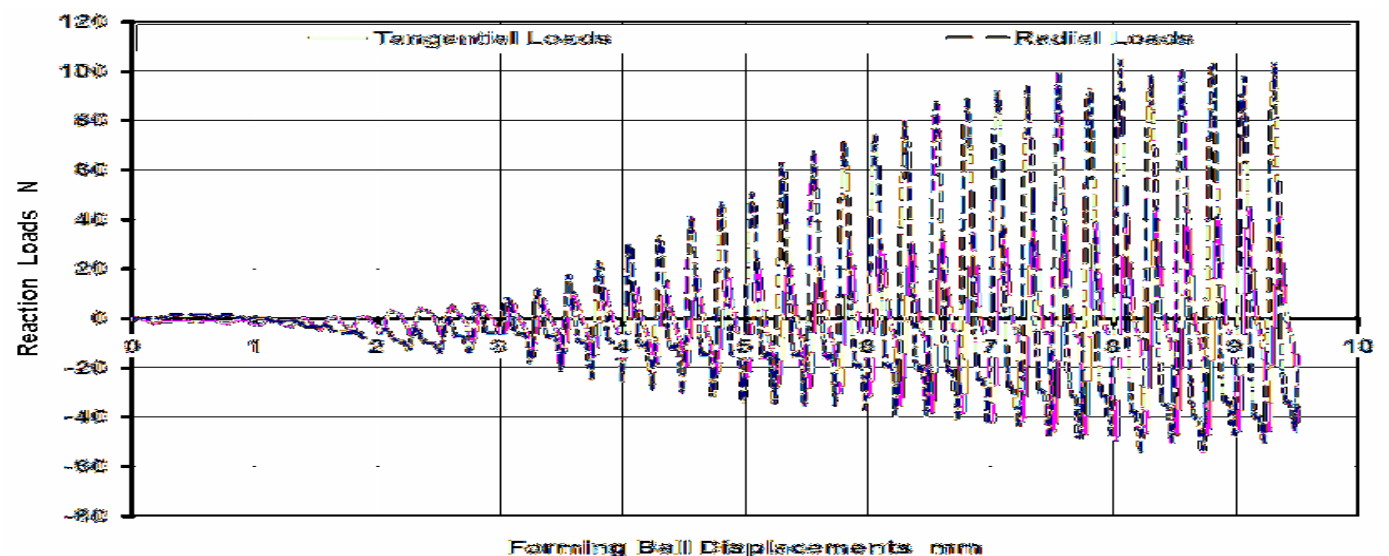

Figure 17: Radial and tangential reactions at a middle location along the tube inner surface 


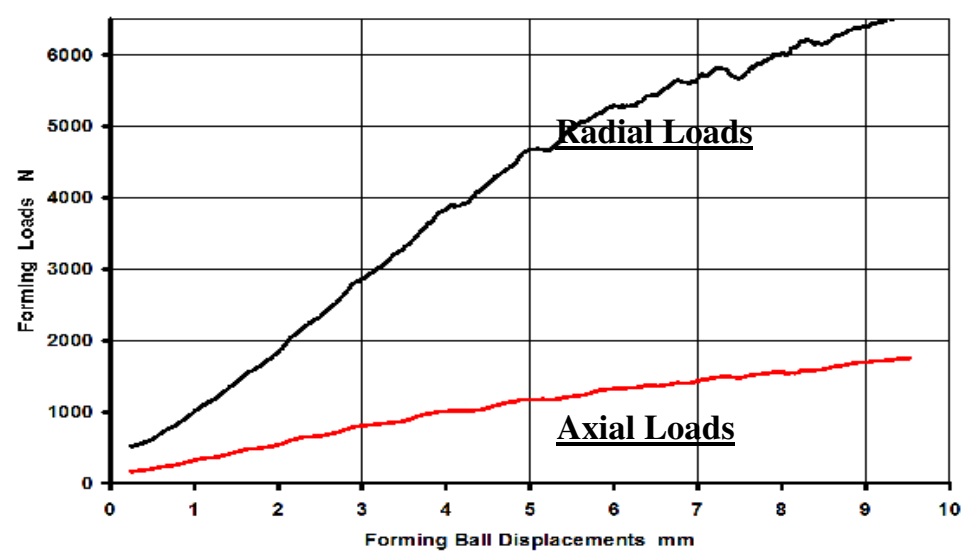

Figure 18: The radial and axial forming loads at one forming ball.

\section{THE NEW PROPOSED BALL SET}

A new proposed design is presented and modeled to reduce the severity of built up formation under the forming ball, the folding formation and the load fluctuation at the spline tooth root. The proposed design is based on increasing the number of balls engaged at the same time in the deformation zone. This requires smaller ball diameters and multistage staggered balls. Figure 19 shows a sectional view in this new proposed design. In this design the thickness reduction is divided by four rows of balls each row has six balls distributed evenly on the circumference. The $1 \mathrm{~mm}$ thickness reduction per ball is reduced to $0.25 \mathrm{~mm}$ allowing a smaller ball diameter of $7.5 \mathrm{~mm}$. The rows are separated by $4 \mathrm{~mm}$ and rotated $30^{\circ}$ from each other.

Figure 20 shows the FEM of this design. The model has 24 contact pairs, 11544 nodes, 38424 elements and 31,756 DOF with a maximum wavefront of 54 . The sharp increase in the number of elements has significantly increased the calculation time and altered the convergence stability. The simulation was crashed after $180 \mathrm{hrs}$ due to the over sized results file (50GB). The ball axial displacement at crash was 6.85 $\mathrm{mm}$ that required 24,459 iterations.

By examining the achieved results, the new design has shown ability to significantly reduce the built up formation in the front of the forming balls, (Figure 21). The maximum radial strain (0.67) which is lower than that of the conventional setup which is 0.9 as shown in Figure 16. Also, the reactions at the inner surface of the spun tube have shown significant improvements in the radial load fluctuation which is responsible for the folding problems. The radial reactions turned to be positive all the time, as shown in Figure 22, which means that the tube inner surface is pressed towards the mandrel with no separation. This will significantly prevent the creation of folding at the splines inner surface. On the same hand the load fluctuations in the tangential direction have been reduced significantly as shown in Figure 22. This fluctuation reduction in the tangential loads, which are responsible of the tooth root failure, will significantly increase the spline tooth life. It is worth noting that reducing the thickness reduction per forming ball in the new design, from $1 \mathrm{~mm} / \mathrm{ball}$ to $0.25 \mathrm{~mm} / \mathrm{ball}$, has resulted in reducing the spline height (Figure 21). This shows the limitation of the new design that it works fine for the tubes with small thickness. 


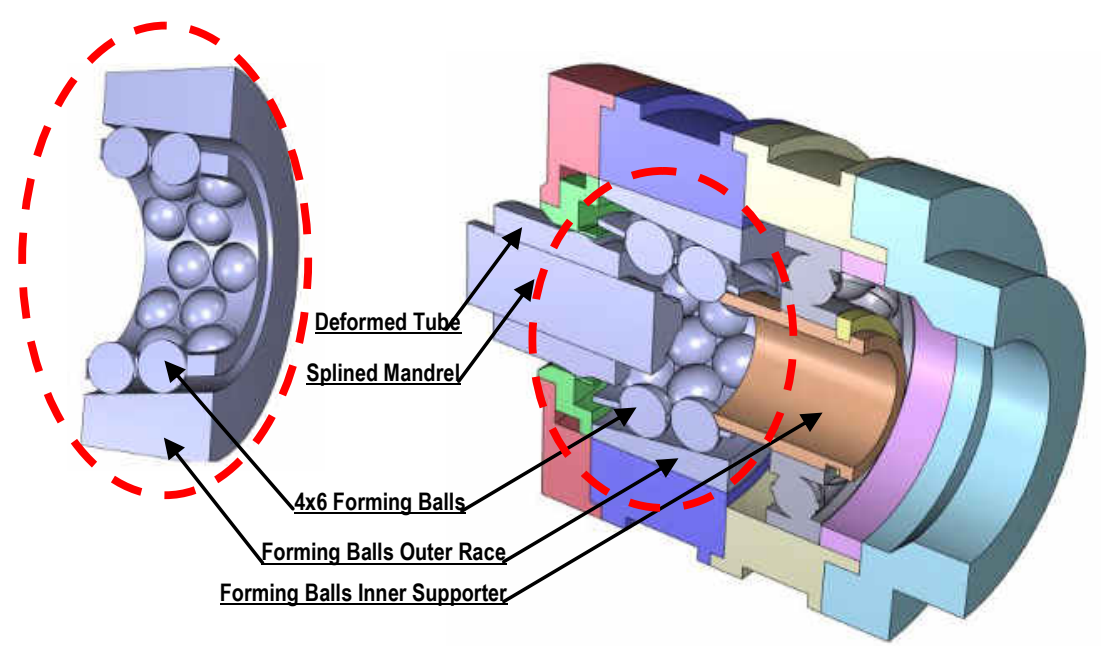

Figure 19: The proposed design for a new ball set for tube spinning of inner grooved tubes
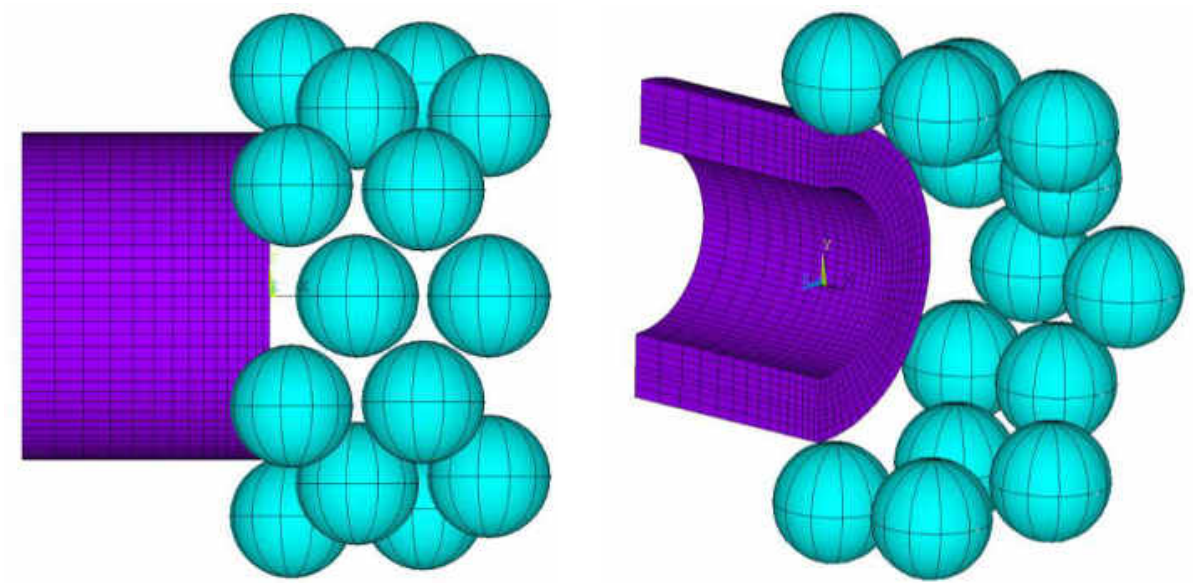

Figure 20: The finite element model of the proposed design
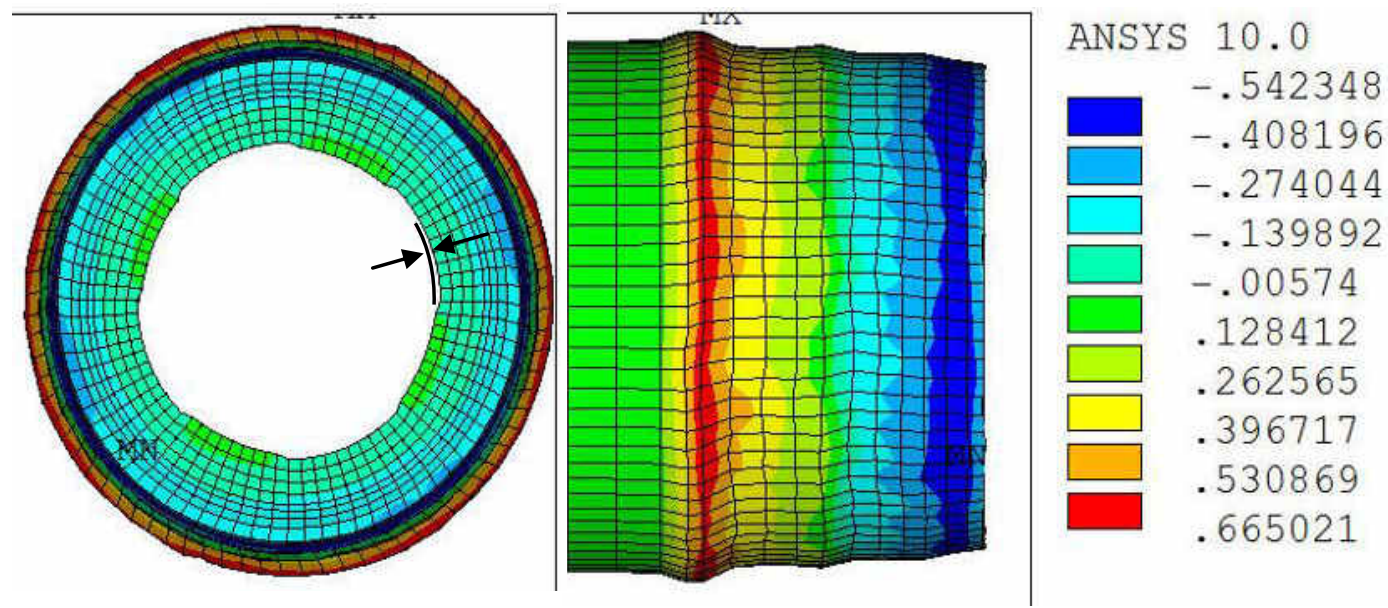

Figure 21: The radial strain in the spun tube by the new triple action ball set design 


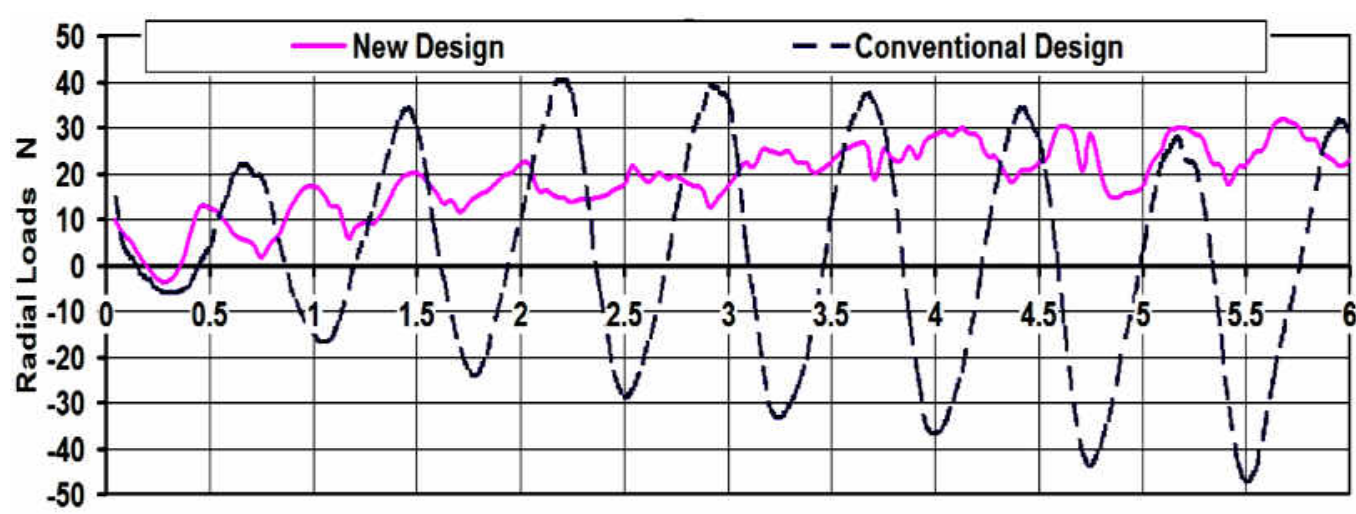

Forming Ball Displacements mm

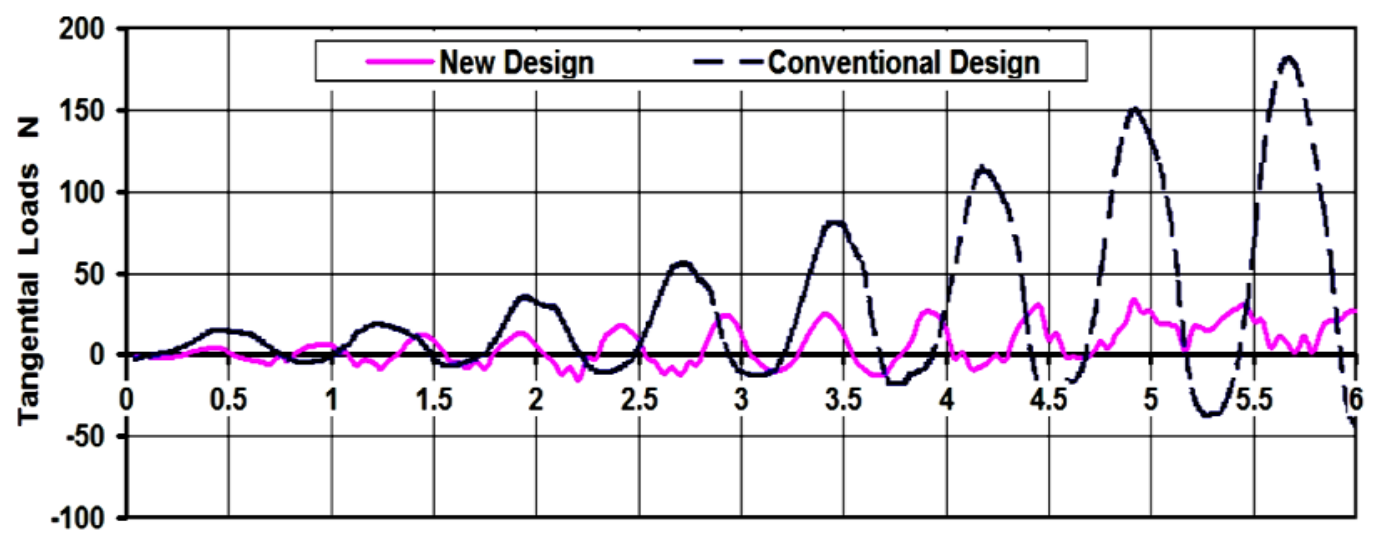

Forming Ball Displacements $\mathrm{mm}$

Figure 22: Comparison between radial and tangential reactions for the new and conventional ball sets

\section{CONCLUSIONS}

Recent development of tube spinning of macro and micro inner grooved tubes and inner geared drums face many challenges. The most important ones are; material built up formation in front of the forming balls, material folding at the tube inner surface, and the forming mandrel failure due to load fluctuations at the root of the forming tooth. These problems have been addressed separately in the literature without a unified approach to simultaneously overcome them. The current study proposes a new ball set design that is claimed to be able to overcome these problems simultaneously. A finite element simulation model for the conventional and the new proposed designs is built. The conventional ball set contains four balls lie in the same plane. The proposed design contains 24 balls distributed in four planes, having 6 balls in each plane. The first plane is set to suppress the built up formation, the second and third plane are set for the main forming process, the fourth plane is set for suppressing the load fluctuation. Each two consecutive planes are shifted by $30 \mathrm{deg}$ from each other to suppress the folding creation. The new design has shown the potential to significantly reduce the built up formation in the front of the forming balls. Also, the reactions at 
the inner surface of the spun tube have shown significant improvements in both the radial load fluctuation which is responsible of the folding problems and the load in the tangential direction which is responsible of the tooth root failure. Since the new design uses smaller ball sizes when compared with that used in conventional design its use is limited to the tubes with small thicknesses.

\section{REFERENCES}

[1] Kalpakjian, S. and Rajagopal, S., "Spinning of Tubes: A Review," J. Applied Metalworking, American Society for Metals, Vol. 2, No. 3, 211-223, July (1982)

[2] Wong, C.C., Dean, T.A., Lin, J., "A review of spinning, shear forming and flow forming processes," International Journal of Machine Tools \& Manufacture, 43, 1419-1435, (2003)

[3] Renne, I.P., and Smirnov, V.V., "s.a. Uber die Bestimmung der optimalen Werkzeugabmessungen beim Abstreck-drucken mittels Kugeln," Umformtechnik, 4, 17-23, (1970)

[4] Heidel, K.H. and Kuhmel, S., "Verfahrensoptimierung des Abstreckdruckens mit Kugeln fur tiefgezogene Napfe," TH Karl-Marx-Stadt., (1979).

[5] Rotarescu, M.I., "A theoretical analysis of tube spinning using balls," Journal of Materials Processing Technology 54, 224-229, (1995)

[6] Saeki, C., and Nishibe, M., "Inner grooving process for a metallic tube," US Patent: US 4,876,869, (1989)

[7] Sakaisha, C., "Inner grooved tube forming apparatus," US Patent: US 5,724,844, (1998)

[8] Tang, Y., Chen, C.Z., Zhang, F.Y., and Lu, D.G., "Oil-filled and pressured spinning of the copper inner spiral fin tube," Forging Stamp. Technology, 3, 3538 , (1998).

[9] Zhang, Z.D., Zhao, Z.D., Wang, J.A., and Shao, M.Z., "Analysis and study on the shaping process of inner grooved copper tube tooth," Forging Stamp. Technol., 62, 39-40, (2005).

[10] Shu-yong, J., Kemin, X., Chunfeng, L., and Zhengyi, R., "Spinning Deformation Criteria of Thin-walled Tubular Part with Longitudinal Inner Ribs," Journal of Wuhan University of Technology - Mater. Sci. Ed.,Vol. 21 No.4,Dec. (2006)

[11] Groche, P., and Fritsche, D., "Application and modeling of flow forming manufacturing processes for internally geared wheels," International Journal of Machine Tools \& Manufacture, 46, 1261-1265, (2006)

[12] Shu-yong, J., Zheng-yi, R., Bin, W., and Gui-xiang, W., "General issues of FEM in backward ball spinning of thin-walled tubular part with longitudinal inner ribs," Trans. Nonferrous Met. SOC. China, 17, 793-798, (2007)

[13] Guang-Liang Zhang, Shi-Hong Zhang, Bing Li, and Hai-Qu Zhang, "Analysis on folding defects of inner grooved copper tubes during ball spin forming," Journal of Materials Processing Technology, 184, 393-400, (2007)

[14] Tang, Y., Chi, Y., Chen, J.Ch., Deng, X.X., Liu, L., Liu, X.K., and Wan, Zh.P., "Experimental study of oil-filled high-speed spin forming micro-groove fin-inside tubes," International Journal of Machine Tools \& Manufacture, 47, 1059-1068, (2007) 
[15] Shuyong J., Zhengyi R., Chunfeng L., and Kemin X., "Role of ball size in backward ball spinning of thin-walled tubular part with longitudinal inner ribs," Journal of Materials Processing Technology, 209, 2167-2174, (2009)

[16] Jiang Shu-yong, Zheng Yu-feng, Ren Zheng-yi, and Li Chun-feng, "Multi-pass spinning of thin-walled tubular part with longitudinal inner ribs," Trans. Nonferrous Met. Soc. China 19, 215-221, (2009)

[17] Tang,Y., Lu, L.,Wang, Q., and Zhao, X., "Experimental and FEM study on Sinking of Miniature Inner Grooved Copper Tube," Journal of Materials Processing Technology, 209, 5333-5340, (2009),

[18] Xue Kemin, Wang Zhen, Lu Yan, and Li Kezhi, "Elasto-plastic FEM analysis and experimental study of diametral growth in tube spinning," Journal of Materials Processing Technology 69, 172- 175, (1997)

[19] Kemin X., Yan L., Xianming Z., "The disposal of key problems in the FEM analysis of tube stagger spinning," 69, 176-179, (1997)

[20] Y. Xu, S.H. Zhang, P. Li, K. Yang, D.B. Shan, Y. Lu, “3D rigid-plastic FEM numerical simulation of tube spinning," Journal of Materials Processing Technology, 113, 710-713, (2001)

[21] Hua, FA, Yang, YS, Zhang, YN, Guo, DY, Tong, WH, and Hu, ZQ, "ElastoPlastic FEM Analysis of Residual Stress in Spun Tube," J. Mater. Sci. Technol., Vol.20 No.4, 379-382, (2004)

[22] Hua, FA, Yang, YS, Zhang, YN, Guo, MH, Guo,D.Y., Tong,W.H., and Hu,Z.Q., "Three-dimensional finite element analysis of tube spinning," Journal of Materials Processing Technology 168, 68-74, (2005)

[23] Moreira, LP, Rodrigues, G, Lopes, LCR, "Finite element analysis of the tube flow forming process," International Journal of Mechatronics and Manufacturing Systems, Vol. 1, No.2/3, pp. 218 - 231, (2008)

[24] Parsa, MH, Pazooki, AMA and Ahmadabadi, MN, "Flow-forming and flow formability simulation", Int. J. Adv. Manuf. Technol., Springer, Volume 42, Numbers 5-6, 463-473, (2009)

[25] Wong, CC, Danno, A, Tong, KK, and Yong, MS, "Cold rotary forming of thinwall component from flat-disc blank," Journal of materials processing technology, 208, 53-62, (2008)

[26] Roya, MJ, Klassen, RJ, and Wood, JT, "Evolution of plastic strain during a flow forming process," Journal of materials processing technology, 209, 1018-1025, (2009)

[27] Doege, E, Deac, V, and Rotarescu, MI, "Experimental research and FEM analysis of steel behavior during tube flow-turning using balls," $5^{\text {th }}$ ICTP, Columbus, Ohio, 547-552, (1996) 


\section{تصميم جليد لمجموعة كرات التثكيل في عملية تدويم الأنابيب ذات الأخاديد الداخلية الطولية}

تعتبر عملية تدويم الأنابيب من عمليات التتكيل القديمة، وبرغم قدمها إلا أنها حديثا أصبحت مفضلة

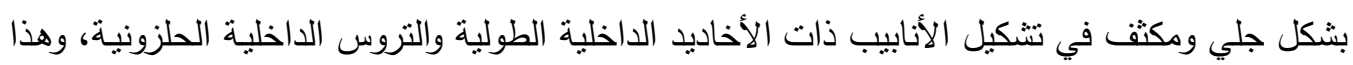

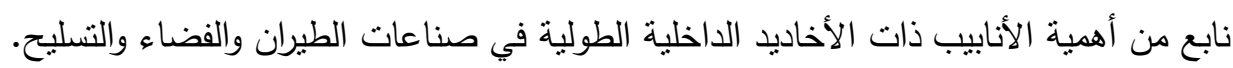

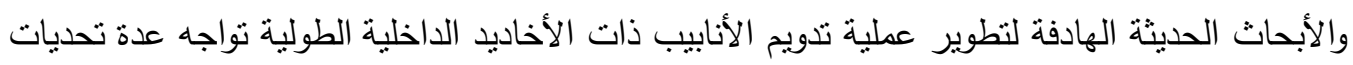

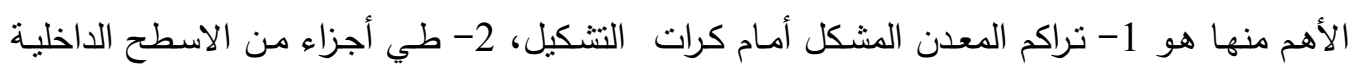

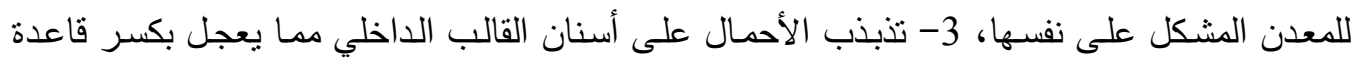

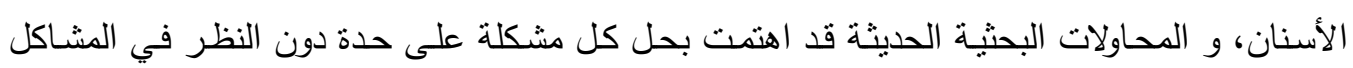
الأخرى مما أدى الى استحالة توفيق هذه النتائج وتطبيقها معا في آن واحد.

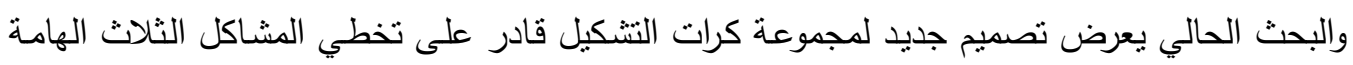

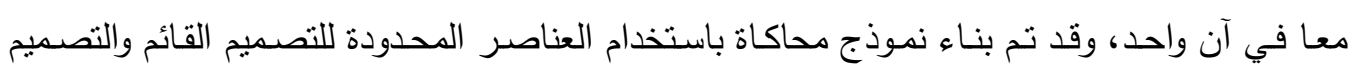

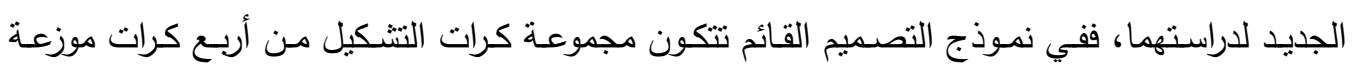
بالتساوي دائريا في نفس المستوى أما في نموذج التصميم الجديد تتكون مجموعة كرات التشكيل من 24

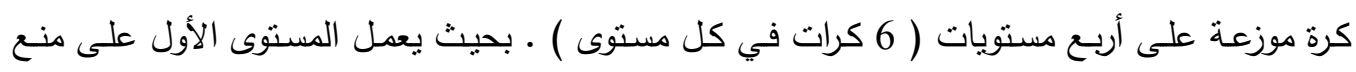

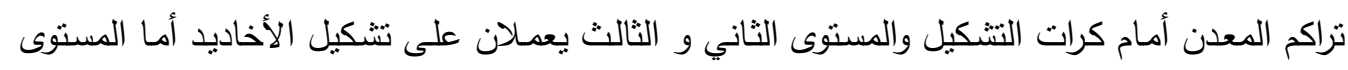
الرابع فيعمل على منع تذبذب الأحمال، وكل مستوى ينحرف عن المستوى الذي يليه بمقدار لمنع طي أجزاء السطح الداخلي على نفسها. وباختبار نتائج نموذج المحاكاة للتصميم الجديد ومقارنتها مع نتائج نموذج المحاكاة للتصميم القائم تبين

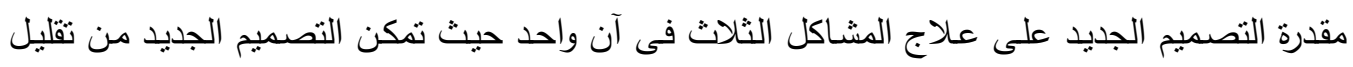

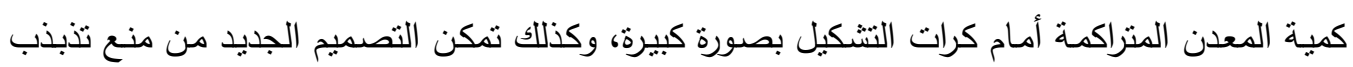

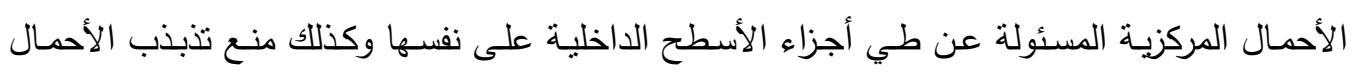

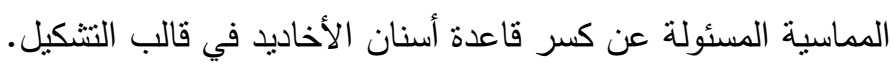

